\title{
Using Photovoice to Derive the Shared Experiences of Adolescents at a Camp for Students with Autism Spectrum Disorders
}

\author{
Matthew Collier, Ph.D. \\ Lander University \\ 320 Stanley Ave. \\ Greenwood, SC \\ United States \\ Sandra D. Devlin, Ed.D. \\ Mississippi State University \\ Mail Stop 9705 \\ Mississippi State, MS \\ United States
}

\begin{abstract}
Autism spectrum disorder (ASD) is a disability characterized by social communication deficits, repetitive and restrictive behaviors, and language and communication deficits. Its prevalence among the general population has led to increased efforts to intervene effectively during childhood and adolescence. Prior quantitative and qualitative research suggests that camps are an effective setting to deliver social skills intervention for children with ASD; however, there are gaps in research that need to be addressed, such as a lack of empirical qualitative evidence, difficulty with language and communication issues inherent to ASD, and limited reliable studies involving the photovoice methodologies. The research questions designed to address such gaps asked what a camp for adolescents with ASD might mean to participants and whether such a camp might produce a change in belonging, self-confidence, and independence among its campers. As such, this study employed the photovoice qualitative methodology to interview 8 adolescent males about their experiences at a social skills camp for boys with autism in the southeastern United States of America. Results of phenomenological qualitative analysis suggest that the most dominant themes expressed by campers were Positive Emotions, Socialization, Unique Experiences, Collective Identity, and SelfImprovement. The interplay and linkages between these themes revealed that the security of belonging with a group of like-minded peers resulted in increased independent experiences and self-confidence among participants at camp.
\end{abstract}

Keywords: autism spectrum disorder, adolescent, summer camp, photovoice, social skills

\section{Introduction}

One of the most challenging disabilities facing educators today is autism spectrum disorder (ASD) (Hedges, Kirby, Sreckovic, Kucharczyk, Hume, \& Pace, 2014). ASD is a neurodevelopmental disorder characterized by deficits in social functioning and communication with restricted interests and repetitive behaviors (American Psychiatric Association, 2013). The Centers for Disease Control rate current prevalence of ASD at 1 in 59 children. More specifically, the prevalence rate is four times more common among boys than girls (Baio et al., 2018).

Children with ASD typically have negative outcomes transitioning into adulthood and living independently (Cederlund, Hagberg, Billstedt, Gillberg, \& Gillberg, 2008; Howlin, Goode, Hutton, \& Rutter, 2004; Lawrence, Alleckson, \& Bjorklund, 2010). One area of difficulty, specifically, lies with developing and maintaining interpersonal relationships. Lawrence et al. (2010) wrote that individuals with ASD have "social impairments [that] make it difficult for those affected to comprehend social rules or function within expected social norms, which often leads to interpersonal rejection, exclusion from social groups, and other forms of social failure" (p. 235). They added that common social pragmatics impairments that cause this could be a lack of reciprocity in social exchange, poor speech prosody, and difficulty expressing and comprehending emotions. These struggles can have grave consequences as an adult. White, Keonig, and Scahill (2007) warned that social skill deficits within individuals with ASD may be harbingers for mood and anxiety disorders in later development. Moreover, these same deficits may make individuals with ASD more vulnerable to peer victimization and bullying (Humphrey \& Symes, 2010) and sexual exploitation (Sullivan \& Caterino, 2004). With this in mind, it is imperative that individuals with ASD are taught appropriate social skills during early phases of development. 


\section{Literature Review}

Typically, children with ASD are taught such social skills in educational settings through special education services (Hedges et al., 2013). However, there is a growing body of research that supports supplementing instruction in educational settings with camp-based or summer treatment settings (Maich, Hall, van Rhijn, \& Quinlan, 2015; Mitchell, Mrug, Patterson, Bailey, \& Hodgens 2015; Rutherford \& Schreiber, 2015; Walker, Barry, \& Bader, 2010). Unfortunately, while there is an abundance of quantitative data rating the efficacy of camp-based treatment, there were limited qualitative data on the subject. One exemption to this paucity was Fullerton, Branna, and Arick's (2002) study, which examined positive outcomes of inclusive programs on students with disabilities across 14 camps and outdoor schools. While this investigation did describe positive effects for students with ASD who participated in general population camps, it did not look at a camp purely for individuals with ASD. Plus, it discussed a variety of disabilities, not solely ASD. Furthermore, the researchers only interviewed counselors and parents, neglecting to derive any data from the students themselves, something the current study hoped to achieve, as first-hand qualitative data leads to stronger research conclusions.

Photovoice is a qualitative research methodology that shows great promise in eliciting rich responses from interviewees by allowing participants to take pictures related to a predetermined theme and using said pictures to direct interviews. The resulting dialogue surrounding said pictures creates potent data (Plunkett et al., 2013). Harley and Hunn (2014) note that "children and adolescents in treatment may not always possess the verbal skills to fully express their feelings about particular topics. The use of photography offers a non-threatening manner in which to share sensitive topics with social workers and other adults" (p.13). Another study successfully employed photovoice with children with ASD, adding that photo voice empowered the children ... as active collaborators and shifted the power imbalance in the relationships between researcher and research participants ... especially given that children with ASD have difficulties engaging in verbal modes of communication with other people (Whitaker, p. 559).

As Plunket, Leipert, and Ray (2013) state, it is "useful as a research method to elicit rich data about the lived experience, which is often sought through phenomenology" (p. 157). Also, due to the communication deficits inherent to the disability of ASD, other qualitative methodologies would likely not yield the most potent information. As such, photovoice assisted in mediating communication gaps between the interviewer and interviewee. Given, Opryshko, Julien, and Smith (2015) support this notion by saying "Photovoice has proven to be a method for engaging groups who may have difficulty articulating their views in traditional research" (p. 3).

Unfortunately, the two studies examined that directly involved individuals with ASD had many flaws in research design that contributed to limited results, primarily due to lack of qualitative triangulation techniques and inconsistent data collection methodologies (Carnahan, 2006; Ha \& Whittaker, 2016). The present study attempted to address this and other aforementioned deficits.

\section{Method}

Upon arrival at camp, the subjects were provided disposable cameras and asked to take pictures of "what about camp is special." On the third day of camp, the pictures were given back to the participants, and, using an interview guide, the researchers discussed each picture with each individual student. After the individual interviews, a group discussion was held to assist in reinforcing and adding to the shared experience of the campers. The interviews were digitally recorded, transcribed verbatim, and analyzed using NVivo and qualitative description (Sandelowski, 2000). Recurrent themes were derived from the analysis. To assist in reliability and validity of data, the photovoice results were supplemented with three observations of the participants during camp activities, as well as data derived from the SSISRS. Furthermore, a peer reviewer also analyzed the qualitative data to confirm findings.

\section{Research Site}

The participants for this study came from a social skills intervention camp designed for adolescents with ASD held every summer for six days at a university within a small southeastern city. Away from their parents' care, campers resided in a college dormitory and participate in social skills lessons and group activities. Research participants were adolescents between the ages of 13 and 18 with an educational diagnosis of ASD. Since there were no female campers to select from, only male adolescents were used. All were either in middle school or high school. Only first year attendees were allowed to participate to ensure reliability of this year's intervention results. Random sampling was employed to choose participants. Geographical origin of the subjects varied, as campers travel from around the country to participate in camp. However, all interviewing and group discussion took place on the site of the camp. Pseudonyms were randomly generated and assigned to protect personal identity. Participants were identified as Ray, William, Robert, David, Ernest, Jonathan, Miles, Jason. 


\section{Instruments}

Photovoice was the qualitative instrument used to acquire the majority of the qualitative data. Photovoice is a powerful phenomenological approach to qualitative inquiry in which individuals are instructed to take pictures of experiences, and then were subsequently interviewed with the photographs as the dialogue guide (Wang \& Burris, 1994). The Social Skills Improvement System Rating Scales (SSIS-RS) was also used as a quantitative measure to determine efficacy of day-camp treatment. The SSIS-RS measures social skills such as communication, cooperation, assertion, responsibility, empathy, engagement, and self-control; competing problem behaviors such as externalizing, bullying, hyperactivity/inattention, internalizing, and autism spectrum; and academic competence, such as reading achievement, math achievement, and motivation to learn. As the camp did not have academic instruction as a component, and the duration of camp limited the ability to affect problem behaviors significantly, only the scales revolving around social skills were used. The social skills lessons implemented by camp staff were generated within a graduate classroom prior to the start of camp. All were approved by the presiding special education professor in order to ensure efficacy, and covered social skills and self-determination skills. Lastly, three observations were conducted to reinforce any potential findings.

\section{Data Collection}

The SSIS-RS was administered to participants prior to the start of camp, and then again on the final day. The photovoice instrument delivery followed these stages: 1 . Camera orientation session; 2 . Collection of photographs and logbooks; 3. Individual photo-sharing sessions and interviews; and 4. Dialogical group conversation and group photo sharing session. In the first stage of the process, the campers were given disposable cameras and instructed to take pictures over the subsequent 2 days of "what makes camp special." They were also instructed to take no more than 27 photographs (the number of pictures available on most disposable cameras). The participants were also given a logbook at the orientation session in which they wrote insights related to the photos as they were taken; these insights theoretically assisted participants to provide data as it occurred to them and help prevent loss of data and perspective due to time. Every night, the researcher collected the cameras and logbooks to ensure that the participants did not lose track of them, and then in the morning returned the materials. In the second stage, the cameras and logbooks were retrieved, the pictures developed, and the logbooks transcribed. In the third stage, in-depth interviews were conducted with each individual camper, examining each photo they took one-by-one and using an interview guide. Finally, in the last stage, campers participated in a group interview and were asked to share their most important photos with the group of participants while discussion was facilitated by the researcher. All interviews and discussions were digitally recorded and transcribed.

Finally, three observations were conducted throughout camp to assist in the triangulation of data. In these observations, the primary researcher placed himself apart from the group being observed and took written notes while the group itself was audio recorded. Three different activities were observed: breakfast, a social skills lesson, and the camp talent show. Each observation lasted thirty minutes and was audio recorded. A map of each observation location was drawn to aid in analysis, and the researcher took copious notes of specific and seemingly important situations as they occurred. Results of these observations reinforced findings resulting from the SSIS-RS and interview data. Ultimately, the logbooks yielded no information; campers neglected to employ them in remembering moments related to photos taken.

This study employed phenomenological qualitative analysis. Creswell (2013) suggests using Moustakas' modification of the Stevick-Colaizzi-Keen method for the analysis of phenomenological data. In the first step of this process, the researcher, in an effort to establish subjectivity, described their own personal experience with the phenomenon under study. As such, the researchers wrote a full description of how they perceived camp to be positively benefitting campers in order to attempt to set aside personal experiences. In the next step, the researcher found significant statements within the data, so they then examined the interview and discussion transcripts in order to find statements related to how the campers experienced camp, treated each statement as having equal worth, and, using NVivo, developed the statements into a list, ensuring that they were non-repetitive and non-overlapping. In the next step, the researcher classified themes derived from statements within the transcripts and created codes that represented said themes. Therefore, the researcher in this study identified significant statements centered on the primary components of the study and coded them with beginning thematic codes and emergent thematic codes, as informed by the collective identity framework and prior research designs. For example, when coding began, extra attention was paid to particular statements that correlated to the elements of collective identity, as outlined by Ashmore, Deaux, \& McLaughlin-Volpe (2004): self-categorization, evaluation of the perceived identity, importance of group membership, attachment and sense of interdependence, social embeddedness, behavioral involvement, and content and meaning of the individual's self-attributed characteristics, ideology, and narrative. Finally, aggregated, multi-dimensional themes were developed by taking repeated codes and correlating and grouping them into larger units of information. 


\section{Reliability and Validity}

The SSIS-RS has been normed on a nationwide sample totaling 4,700 children and adolescents ages 3-18 across 36 states. Gresham, Elliot, Vance, and Cook (2011) note that "the SSIS-RS shows strong psychometric properties in terms of internal consistency and test-retest reliability estimates" (p. 37) and that it "offers researchers and practitioners assessing social behavior of children and youth a broader conceptualization of key social behaviors and psychometrically superior assessment results" (p. 27).

As to issues of the validity and reliability of the photovoice methodology, Given, Opryshko, Julien, and Smith (2015) remark that because participants not only provide data, but select photographs and discuss themes and issues, they are involved in the data analysis process. "This increased participation adds to the validity of Photovoice studies by reflecting results that are determined and emphasized by the community studied, not by the researcher" (p. 3). They also note that in photovoice multiple streams of information are used, which triangulates the research, strengthening the instrument reliability and validity. Triangulating data between both individual and group discussion further assisted in strengthening research validity.

Other methods were used to assist in triangulation of data. First, any conclusions gleaned from interviews were compared against the aforementioned observations. Also, peer-checking was conducted to ensure that the researcher did not misidentify themes. Moreover, prior to the start of the study, a document was created in which biases were preidentified. An example statement from the biases document follows: I am a special education teacher. As such, I have nine years of experience that may influence my line of thinking. I also feel that people with autism struggle in their daily life. On top of that, adolescence is a trying period anyway. It is important for individuals to live outside of their comfort zone and develop safe and appropriate friendships along the way.

By identifying biases the researcher was able to be mindful of them throughout the course of the study, theoretically reducing their influence on the final results.

\section{Data Analysis}

The analysis of the interview data was conducted using NVivo. NVivo is an aggregative software designed to organize and assist in analysis of qualitative data. Through NVivo, planned and emergent themes were coded, as well as memos created to remember important thoughts as they occurred. For example, this memo was created after analyzing a handful of interviews: "It is interesting to note that across the interviewees, the majority of comments related to having fun or friendship or even the photos themselves are of off-camp activities. This makes sense, since at-camp activities tend to be lesson based. However, it was still worth noting. Perhaps the students enjoyed these things because they are unique experiences, and by sharing these unique experiences with others it helps with bonding?" This eventually turned into a major thematic category that is examined further in the results section. Similarly, annotations were added to especially salient quotes to assist with the final data analysis phase. One example of an annotation is a comment made after noticing a second mention of independence: "I'm noticing a lot of mentions of doing your own thing and independence with (the individual)." Eventually, this thought was chased further and determined that independence was a recurrent theme. Finally, NVivo allowed the researcher to do word frequency queries, as reflected in the results section.

Analysis began with the researcher examining the interview transcripts while looking for codes related to the aforementioned collective identity components outlined by Ashmore, Deaux, \& McLaughlin-Volpe (2004). As coding progressed, other themes emerged from repeated statements, such as emotion, perception of camp, camp experiences, and shared experiences, to name a few. All initial and emergent codes are represented in Table 1. After coding and re-coding the transcripts to ensure no themes were missed, all of the codes were ordered from most represented to least represented (Table 2). 
Table 1 - Initial and Emergent Codes

\begin{tabular}{|c|c|c|c|}
\hline Initial Codes & & Emergent Codes & \\
\hline Parent Code & Sub-code & Parent Code & Sub-code \\
\hline \multirow[t]{4}{*}{ Shared Experiences } & Shared Goals & Emotion & Positive - Self \\
\hline & Shared Actions & & Positive - Others \\
\hline & Shared Orientations & & Negative - Self \\
\hline & Belonging & & Negative - Others \\
\hline \multirow{4}{*}{ Camp Experiences } & Independence & Perception of Camp & Negative Experiences \\
\hline & Friendship & & Unique Experiences \\
\hline & Fun & Choices & \\
\hline & Learning & Autism Characteristics & Aggressiveness \\
\hline \multirow[t]{3}{*}{ Self-categorization } & Self-placement & & Anger \\
\hline & Goodness-of-fit & & Anxiety/Paranoia \\
\hline & Perceived Certainty & & Can't Name Emotion \\
\hline \multirow{2}{*}{ Evaluation } & Private Regard & & Communication Limits \\
\hline & Public Regard & & Lack of Empathy \\
\hline \multirow[t]{2}{*}{ Importance } & Explicit Importance & & OCD \\
\hline & Implicit Importance & & Pragmatics \\
\hline \multirow[t]{3}{*}{ Attachment } & Interdependence & & Social Skills \\
\hline & Attachment & Camp Experiences & Adventure \\
\hline & $\begin{array}{l}\text { Interconnection of Self } \\
\text { and Others }\end{array}$ & & Feeling At Ease \\
\hline Social Embeddedness & & & Friendship \\
\hline Behavioral Involvement & & & Fun \\
\hline \multirow[t]{10}{*}{ Content and Meaning } & $\begin{array}{l}\text { Self-attributed } \\
\text { Characteristics }\end{array}$ & & Independence \\
\hline & Ideology & & Learning \\
\hline & Narrative & & Overcoming Disability \\
\hline & & & Security \\
\hline & & & $\begin{array}{l}\text { Socialization } \\
\text { Opportunities }\end{array}$ \\
\hline & & Shared Experiences & Belonging \\
\hline & & & Bonding \\
\hline & & & Shared Actions \\
\hline & & & Shared Goals \\
\hline & & & Shared Orientation \\
\hline
\end{tabular}


Table 2 - Code Frequency (Prior to Consolidation)

\begin{tabular}{|l|l|}
\hline Code & References (Sources) \\
\hline Positive - Self & $65(10)$ \\
\hline Friendship & $57(9)$ \\
\hline Positive - Others & $55(8)$ \\
\hline Fun & $53(10)$ \\
\hline Unique Experiences & $44(11)$ \\
\hline Shared Actions & $41(9)$ \\
\hline Socialization Opportunities & $29(8)$ \\
\hline Independence & $25(9)$ \\
\hline Feeling at Ease & $22(8)$ \\
\hline Bonding & $19(7)$ \\
\hline Shared Orientation & $18(6)$ \\
\hline Learning & $16(7)$ \\
\hline Overcoming Disability & $14(5)$ \\
\hline Security & $11(4)$ \\
\hline Interconnection of Self+Others & $11(5)$ \\
\hline Shared Goals & $9(4)$ \\
\hline Self-placement & $6(3)$ \\
\hline Belonging & $6(4)$ \\
\hline Negative - Others & $6(4)$ \\
\hline Negative Experiences & $5(3)$ \\
\hline Adventure & $5(2)$ \\
\hline Social Embeddedness & $4(2)$ \\
\hline Interdependence & $4(3)$ \\
\hline Self-attributed characteristics & $4(3)$ \\
\hline Negative - Self & $4(3)$ \\
\hline Behavioral Involvement & $2(2)$ \\
\hline Attachment & $2(1)$ \\
\hline & \\
\hline
\end{tabular}

From there, codes were grouped together codes into smaller, more concentrated thematic groups: positive emotions, socialization, unique experiences, collective identity, and self-improvement. The resulting multi-dimensional thematic categories, along with the codes that comprise them, are represented in Table 3.

Table 3: Thematic Categories

\begin{tabular}{|l|l|}
\hline Thematic Category & Codes Contained \\
\hline Positive Emotions & Positive \\
& Positive - Others \\
& Fun \\
& Feeling at Ease \\
& Security \\
& Belonging \\
\hline Socialization & Friendship \\
& Shared Actions \\
& Socialization Opportunities \\
& Bonding \\
\hline New Experiences & Unique Experiences \\
& Independence \\
& Adventure \\
\hline Collective Identity & Shared Orientation \\
& Interconnection of Self + Others \\
& Shared Goals \\
& Self-Placement \\
& Social Embeddedness \\
& Interdependence \\
& Self-attributed characteristics \\
& Behavioral Involvement \\
& Attachment \\
\hline Self-Improvement & Learning \\
& Overcoming Disability \\
\hline
\end{tabular}




\section{Quantitative Results}

The results of the SSIS-RS indicated growth among the group for almost all of the social skills sub-scales, as well as the overall standard score $(M=3.13, \mathrm{SD}=9.2)$ and percentile $(\mathrm{M}=2.88, \mathrm{SD}=19.79)$. The subscales that had the most growth were Self-Control $(\mathrm{M}=1.75, \mathrm{SD}=3.20)$, Responsibility $(\mathrm{M}=1, \mathrm{SD}=2.40)$, and Assertion $(\mathrm{M}=0.86, \mathrm{SD}=$ 4.29), while the only subscale that indicated negative change was Communication $(\mathrm{M}=-1.57, \mathrm{SD}=2.88)$. The full results of the SSIS-RS are displayed in Table 4.

\begin{tabular}{|c|c|c|c|c|c|c|c|c|c|}
\hline $\begin{array}{l}\text { Social Skills } \\
\text { Subscales }\end{array}$ & Ray & William & Robert & David & Ernest & Jason & Derrick & Jonathan & $\begin{array}{l}\text { Mean } \\
\text { Change(SD) }\end{array}$ \\
\hline Communication & $18(18)$ & $17(10)$ & $18(18)$ & $16(14)$ & $17(16)$ & $10(\mathbf{1 2})$ & $18(21)$ & $12(9)$ & $-1.57(2.88)$ \\
\hline Cooperation & $18(\mathbf{1 9})$ & $17(13)$ & $15(17)$ & $20(19)$ & $17(16)$ & $16(19)$ & $20(21)$ & $16(15)$ & $0(2.20)$ \\
\hline Assertion & $17(\mathbf{1 9})$ & $14(13)$ & $19(18)$ & $16(11)$ & $12(\mathbf{2 0})$ & $9(9)$ & $21(19)$ & $5(11)$ & $0.86(4.29)$ \\
\hline Responsibility & $16(21)$ & $14(15)$ & 17(19) & $17(15)$ & $13(15)$ & $14(15)$ & $21(21)$ & $15(14)$ & $1(2.14)$ \\
\hline Empathy & $18(18)$ & $10(\mathbf{1 1})$ & $15(17)$ & $13(11)$ & $14(15)$ & $12(15)$ & $18(18)$ & $9(7)$ & $0.375(1.77)$ \\
\hline Engagement & $14(17)$ & $18(12)$ & $17(\mathbf{1 9})$ & $12(12)$ & $16(19)$ & $6(9)$ & $21(21)$ & $16(17)$ & $0.75(3.01)$ \\
\hline Self-Control & $7(\mathbf{1 0})$ & $5(11)$ & $14(14)$ & $6(2)$ & $14(17)$ & $10(15)$ & $17(18)$ & $12(12)$ & $1.75(3.20)$ \\
\hline $\begin{array}{l}\text { Standard Total } \\
\text { Score }\end{array}$ & $\begin{array}{l}111(12 \\
\text { 2) }\end{array}$ & 101(94) & $\begin{array}{l}116(122 \\
)\end{array}$ & $\begin{array}{l}105(93 \\
\end{array}$ & $\begin{array}{l}107(119 \\
)\end{array}$ & $\begin{array}{l}88(\mathbf{1 0 1} \\
)\end{array}$ & $132(\mathbf{1 3 4})$ & 94(94) & $3.13(9.2)$ \\
\hline Percentile & $76(92)$ & $53(34)$ & $85(92)$ & $62(32)$ & $68(88)$ & $22(51)$ & $>99(>99)$ & $34(34)$ & $2.88(19.79)$ \\
\hline
\end{tabular}

Table 4. SSIS-RS Results Note: 1. Pre-test (Post-test). 2. Post-test increases in bold. Post-test decreases in italics

\section{Qualitative Results}

After expanding then collapsing prominent themes together, it was clear that campers experienced camp within five primary thematic categories: positive emotions, socialization, new experiences, collective identity, and selfimprovement.

\section{Positive Emotions}

By far, the most dominant theme expressed was that of positive emotions experienced by campers during their time at camp. This category was created by aggregating the codes Positive - Self, Positive - Others, Fun, Feeling at Ease, Security, and Belonging. All of the campers represented this theme within their interviews, primarily through examples of having fun and feeling at ease.

Running a query through NVivo, the word "fun" or any synonyms thereof were represented a total of 87 times throughout the interviews, with a weighted percentage of $0.76 \%$ overall. This indicates that this particular theme was extremely prevalent, and, not surprisingly, all of the campers represented this theme within interviews. As Jason said, "There's a pattern with most of these pictures [...] the importance of having fun."

Many campers noted that the daily activity of playing board games during downtime was a significant experience. Several of the photos involved campers playing a variety of board games. For example, when queried about the meaning of a picture he had taken of himself and another camper, Ray replied "Having fun playing with [another camper]. Playing battleship" and that the photo made him think about "having fun playing that game." David mirrored this comment on a photo of a group of campers playing Uno: "Uno is very special to me because I like to play cards with my friends." Jonathan also captured a picture of campers playing Uno, and when questioned about the meaning behind it, he offered "They in the camp. [...] They play Uno cards [...] and they're feeling so much good [...] because, um, their brain just make them feel good and awesome." Ernest brought up an interesting observation, that he enjoyed camp, and presumably that others do too, because this camp is different because "some people don't like outdoors" and that the experience of just having recreational indoor downtime with others was enjoyable. He further detailed a situation that pointed to the significance of play during this exchange about a Monopoly experience:

Q: Tell me what is special about this picture.

A: We had just finished our third day. And I took the picture. And it had been quite a long game. And everybody went bankrupt.

Q: How long did y'all play?

A: About three days or four -

Q: Oh, so you played this game over three days?

A: Mmm hmm.

Q: Is that when it was over, or was that - 
A: That was right before - I mean, we were goin' to bed and I took the picture.

Q: Uh huh.

A: Because the way it was all set up everybody had properties, alliances... and I was one against three.

Q: So there were four people playing?

A: Four people playing. Me against Zeke, Mr. Eric, and Andrew. And they had teamed up 'cause they had... Andrew had Boardwalk, and Zeke had, uh, the green properties. And they decided to team up. Mr. Eric just teamed up with them, and eventually Andrew forfeited.

Q: Uh huh.

A: So it wasn't really a good idea, to, cause if I had lost, they would've had to break it up.

Q: That's wild. Um, what does this picture say to you about camp? A: Like, some people call camp dull, but it's really not that dull at all. There's games, there's food, I mean... I when I first started out I really didn't want to come here 'cause I had never been to a camp before, and wanted to find out, and now I love it!

Another example of the ubiquity and prominence of board game playing was explained in the group interview:

Q: Ok, alright, this one is David's. Tell me what is special about this picture.

Derrick: Just playing around. Having fun.

Q: Just playing Uno cards. Is that something that's been going on at camp a lot, or-

ALL: Yes. Yes.

Robert: We play board games...

Ernest: And Monopoly...

Q: What does that say to you about camp and what we do at camp?

Derrick: Just having fun playing board games.

Outside of board games, there were other opportunities for fun to be had, such as in off-camp excursions to various activities and locales. Regarding the trip to the local skating rink, William noted, "Camp - it's a kind of thing it's kind of fun for camp, like to go, like roller-skating." Derrick stated something similar: "We took a trip to the bowling alley, and, um, I met a lot of people, had fun bowling, and that was it." Within the group interview this was also discussed during an examination of a picture of two camper's arm-in-arm at the skating rink:

Derrick: Where were y'all?

David: Skating rink. You can see the games. Behind you, you can see the jackpot machine.

Q: So tell me what is special about this picture?

Derrick: Two friends at the skating rink having fun.

Q: Mhm.

Derrick: Just having a good time.

Overall, fun was a markedly dominant theme. Many of the participants would likely agree with William, who stated, "Camp is a bit of a party."

Besides having general fun, many campers reported a sense of comfort or feeling at ease that they do not experience elsewhere, mainly due to knowing they are accepted and protected by counselors and among similar peers. A good example of this can be found in this exchange with Derrick:

A: There are, I can see that they have positive energy too, and uh, the people I've met they have positive energy, and [counselors], they have positive energy too.

Q: Ok.

A: They've been really nice, um, every, any, if anything I need I just go ask them and they try to help me and they do the best that they can.

Q: Ok.

A: And they just... and if I, um, if someone is bothering me or if I see something I just go tell them and they take care of it and of me.

Robert adds to this when asked why he felt "happy and relaxed" at camp: "Cause you got friends supporting you." Jason also noted that at camp "you can enjoy yourself in any way you want to". Similarly, Derrick said, "I have friends that have my back."

In addition to emotional support, many campers related that they felt physically secure, which added to their sense of comfort. As Derrick said, "the campus is like, secured, so I felt protected." Robert added that he felt excited "because there's lots of people watching after us" and that "it's safe here." During the group session, when Robert repeated this statement, Ernest remarked, "I can see that. Cause the counselors are protective of us." A good summary of this shared sentiment of being free to be oneself can be found in this interview excerpt from Jason:

Q: Alright, tell me what is special about this picture... 
A: It's probably gonna be the same thing every time.

Q: Well, go ahead, tell me - even if you're repeating yourself, it's ok.

A: Being able to have fun with others.

Q: Yeah. So what does that say to you about camp?

A: That I could just... share my enjoyment.

Interestingly, Robert also stated that he felt relaxed because "outside the building how nice it looked" and that he was "enjoying the nature view."

\section{Socialization}

Not surprisingly, the second most prevalent theme was that of socialization, mostly related to friendship, engaging with others in activities, and opportunities for socialization. It was nearly impossible to examine these interviews without observing a statement regarding friends. For example, in response to a photo, Robert stated that it "makes me have a fun time just hanging out with friends." Jason said that there is fun of the "social variety - being able to enjoy something with other people" and that he felt comfortable enough "that I could just talk to other or new people." He also included an anecdote from the first day of camp when examining a picture of him and another camper: "What's special about this picture is because, um, me and [another camper] had just become friends right away because, I mean, dude's kinda cool." He added that camp is "all about making friends" and that at camp "it's almost easy, almost too easy to make friends." He connects this to an emotion by stating that he was "happy that I made a new friend." Derrick echoed this: "it makes me kinda happy that I met some friends here and I met some new friends here and I'm getting to meet with them and talk to them and stuff like that." Ernest summed this up this perfectly: "I've never made so many friends in my life."

The various activities the campers engaged in provided opportunities for bonding and/or socialization to occur, as evidenced by this excerpt from the group discussion about the movie theater:

Q: Was this an activity that you all enjoyed?

Derrick: I did!

Ray: Me too.

Derrick: Cars 3 was a blast!

Q: Was it? Did you enjoy it more going with the camp or going alone, or if you'd gone alone. Derrick: Camp.

Bowling was also an opportunity for bonding and socialization. Ernest noted, "This picture was because everybody went bowling and it was a group thing. There was some competition, but same thing as always: it's a camp field trip. Just getting time with the people we get to know better." Jason also felt this: "You find ways to enjoy yourself with the other people that are here" and that "camp allows me to be around more people." This selection from our one-on-one also exemplifies his feelings regarding friendship at camp:

Q: Ok. I understand. Do you think others feel - I know we kind of got off topic - but looking at this picture do you think others feel the same that you felt, which was that you feel that you could socialize?

A: Yeah.

Q: Ok. Why do you say yeah?

A: I guess just the picture itself can - it gives off a sense of... I don't have the words.

Q: No, you're doing very well. This picture gives off a sense of... what are you trying to say?

A: Friendliness, I guess.

\section{Unique Experiences}

Summer camps provide an opportunity for adolescents to try new experiences and situations. As such, it is unsurprising that the third most salient theme that emerged was that of Unique Experiences, more specifically regarding specific opportunities and independence, as supported in the following exchange:

Q: So what does that picture say to you about camp?

Ernest: That we go on adventures.

Derrick: That no matter where you go, just have fun.

This excerpt reflects a repeated theme: going new places is fun, and camp provides plenty of these types of opportunities. The campers especially reinforced this idea in the group interview, when Robert's photo of an arcade game in the bowling alley sparked this discourse:

Q: So what Robert said about new experiences - what did you say -

Robert: About having fun.

Q: About having fun.

Robert: About trying new things every day. 
Q: Have new things and having fun every day. Is that something everybody else agrees with?

Jason: I totally agree.

Q: Ok. Yeah. Everybody looks like they are nodding in agreement. Jonathan, did you do new things every day?

Jonathan: I'm agree for that arcade game.

Robert also related individually that, for him, going new places gave him "happiness, I mean actually getting out of here for a while" and that he was "happy that we're out and about." In the group interview, he adds that going to places like the cafeteria, for him, meant that "we go on adventures", and that he enjoyed "eating, trying new things." Going new places was an especially powerful experience for Jason, as he related that encourages him to not just stay at home in the future. To him, camp was about "being able to just leave your normal area - just being able to be somewhere else," and that "you don't really have to just stay at home and stay there."

Likewise, the unique opportunities presented by camp allowed these individuals to practice an important life skill: independence. Jason related a particularly powerful experience when a counselor encouraged him to do something that bolstered his self-confidence, which in turn made the other participants relate:

Jaden: She's the one who got me to go on the rock wall.

Q: So you weren't going to go on the rock wall?

Jason: Yeah.

Q: But you did?

Jason: Yeah.

Q: Are you glad you did?

Derrick: She got me to go like six times.

Jason: I guess now I know I could do it.

Q: Yeah.

Ray: Did you reach the top?

Jason: Yeah.

Q: So what does that say to you about what camp does for kids, then?

Ernest: Confidence.

Q: It builds confidence? Or gives kids confidence? Is that what you meant?

Ernest: Yeah. I should have gone on the rock wall.

Outside of boosting confidence, independence provided other new opportunities, as exemplified by Jason, who described experiencing night time in a different way than he ever had before:

Jason: Best time for me.

Q: Is it? Why?

Jason: The medicine has worn off and everything. [...] [It's] just different. I guess you could say somewhat different pieces taken out of my personality.

Q: Yeah. Interesting. So, have you enjoyed that? Like have you enjoyed getting those pieces back in the evening and hanging out with friends?

Jason: Yeah.

For Jason, being able to socialize without the influence of his daily medications was remarkable. Another poignant story comes from William, who described his experience going to see Cars 3:

Q: Was there something different about going to the movies this time than usual?

A: Uh, yes sir.

Q: What was different?

A: Sir - I was being a big boy when it was big, so loud, I just ignored.

Q: Ohhh. Excellent.

A: The loud - the loud noise.

Q: When you go to the movies NOT at camp, does it bother you more about the same or less?

A: Um, maybe - more. It's like - did earplugs.

Individuals with ASD typically have sensory issues and can frequently find loud noises very uncomfortable. In this story, William related that he was able to overcome this aspect of his disability all because of camp. William also offered another example of new, independent experience: "We - like we sleep in our own beds."

\section{Collective Identity}

Although the codes related to collective identity were not as represented as hypothesized, there were still relevant quotes that connected the study to this framework. Jason rather cryptically referred to this when he stated that "we're all here for the same reason." What Jason was referring to was that the camp, ultimately, is for individuals with ASD. 
Ernest recognized this most frequently, and also placed himself within the collective identity group, such as when he said, "It makes you feel glad that people with autism, we're getting to know other people. Learn to fit in..." He also indicates such in this exchange:

A: Ok, let's say I have autism and I scream all the time and I cry all the time, you know that, and people look at me like I'm weird. And then I go to camp and I'm not looked at like I'm weird, I... fit in.

Q: Ok.

A: It's like, "Hey, I'm not the only one."

In fact, Ernest is the only participant who named ASD itself, or even commented that he and other campers lived with it.

\section{Social Skills Improvement}

Finally, although it was the least represented theme, there were several comments made related to camp assisting adolescents with ASD with social skills. Many of the participants made direct comments about the daily social skills and self-determination instruction groups. Robert noted that "I'm learning new things [...] about communicating. And everything they teach me," as well as "about making friends," noting that a certain counselor "taught me how to make friends." Jason also reflected this:

Q: Ok. Um, how does this picture make you feel about yourself during camp?

A: Like I learned a lot.

Q: Like what?

A: I guess myself.

Q: Mmhmm. When you say you learned a lot about yourself, what do you mean?

A: How I socialize with people, I guess.

Q: Ok. In what ways do you socialize with people?

A: Just talking.

Q: Uh huh. So you're saying that camp has... I'm trying to tie it back to what camp has done for you, and made you feel... you're saying that camp has made you feel like...

A: I guess I'm able to talk to more people.

Ernest also described a story about learning:

A: It was the second group day, we were talking about, uh, starting a conversation.

Q: Ok.

A: And everybody was in a circle and talking to the people and making new friends.

Q: Ok.. What does that picture say to you about camp?

A: That even though you still come to camp you still learn some new things.

Perhaps because of such support, camp also provided moments for certain campers to overcome aspects of their disability. Ernest described an example of another camper improving over the week: "I'm glad for Jamie. He's getting better because he's not wearing his headphones as much, he's learned to get along without them. He's getting used to loud noises." Not all campers had such positive notes regarding the instructive components of camp. For example, William said that he felt "a bit, a little bit bored doing all the lessons."

\section{Discussion}

The results indicated that campers at the summer camp represented their experience through discussion and pictures regarding fun and games, feeling at ease, socialization and extending social networks, partaking in unique experiences, experimenting with autonomy and independence, and learning about and improving social skills. To a lesser degree, there was some connection to collective identity theory, but not as much as was anticipated.

The emphasis on having fun and enjoying opportunities to play with each other is a theme that previously had not been reflected among literature. The near constant board game playing reflected in interviews was also witnessed during the planned observations. In the first observation, which occurred very early one morning as sleepy campers were waking up and eating breakfast, two different tables could be observed playing games as campers quietly conversed. It is important to note that board game playing was never a required activity for campers; they naturally gravitated toward the experience. The importance of fun and play is noteworthy, as the potential importance of play in social, linguistic, and cognitive outcomes in children with ASD has been demonstrated across prior studies, such as Kasari et. al (2012) who noted a connection between higher play levels between children with ASD at ages three and four with enhanced language outcomes within the same children at ages eight and nine. As such, the opportunity for camp participants to engage in low-pressure fun activities among like-minded, non-judgmental peers cannot be overstated; in fact, for some campers, camp may have been the only opportunity they have for such prolonged recreational experiences. 
The data also revealed a common sense of security and comfort expressed among the campers during camp. Identification of these concepts are also articulated within other research. For example, parents within Wallace's (2016) study on the impact of a family-centered autism camp reflected that "Being able to go to Camp, let your kids disappear to wherever, and go and know they'll be okay cause they are just like everybody else's kids for once, and listen to something is wonderful." (p. 1450) and "For [my son], it is the opportunity to have the freedom to be himself and to roam [camp] and explore" (p. 1450). These quotes came from parents; the present study is notable in that it allowed individuals with ASD to express said experiences themselves. This is important because there is almost no prior qualitative research on adolescents with ASD in which said individuals express themes themselves. The significance of security and comfort was exemplified further within the third observation, which occurred during the camp talent show. During the talent show, the entirety of the camp audience exuberantly cheered for each act. Acts observed consisted of a camper singing and playing guitar, a camper karaoke rapping, a camper singing, and several campers dancing, respectively. In truth, each act was objectively of dubious quality; however, the audience did not seem to mind whatsoever, and supported the performer regardless. The fact that almost every camper eventually expressed themselves through their talent only indicates even more the level of acceptance they had found within each other.

Research has repeatedly emphasized the importance of socialization of children with ASD. Kasari, Locke, Gulsrud, and Rotheram-Fuller (2011) reported that "children with ASD in general education classrooms are most often on the periphery of their classroom social networks" (p. 540-541). Moreover, they added that "their social networks are smaller than typical classmates, the friendships they identify are less often reciprocated, and the quality of their friendships is poorer" (p. 541). By the same token, van Asselt-Goverts, Embregts, Hendriks, Wegman, and Teunisse (2014) conducted a study comparing the social networks of people with ASD with typical peers. Unsurprisingly, they found that individuals with ASD had smaller social networks, and that people with ASD are frequently unsatisfied with their social networks. This is notable in relation to the present study because almost all of the participants reflected that one of the most enjoyable aspects of camp was their opportunity for socialization and gaining new friends. Camp provided countless opportunities for social engagement, and, as a result, most of the campers, if not all, left camp with new friends and a stronger support network. In all three observations, various campers were repeatedly observed conversing appropriately and hanging out, sometimes even at inappropriate times like during social skills instruction or the talent show. The opportunity for social network expansion was critical for these campers.

The analysis also indicated that a dominant thematic category was the importance of new and unique experiences for campers. This is not a new concept in academic literature. In a qualitative study of a camp for students with visual impairments, Goodwin, Lieberman, Johnston, and Leo (2011) remarked that campers' generally appreciated the "depth of their experiences" and recognized that their "experiences" would "be carried into other contexts and serve them well at other times" (p. 47). Furthermore, these new experiences sometimes resulted in increased autonomy and independence. Counselors from Halsall, Kendellen, Bean, and Forneris's (2016) study of a residential camp noted the importance of encouraging campers "to try something new to help them adapt to being in a new place with new opportunities" (p. 28) as a means of encouraging camper autonomy. This is similar to another counselor statement from the same study: I find that once you can get [campers] to do something they don't want to do and they have a good time, then they are way more interested in doing things that are outside their comfort zone. (p. 28)

Halsall, Kendellen, Bean, and Forneris's (2016) article also stated that camps provide a space for "incremental opportunities to transition from one reality (adolescence) to the next (adulthood)" (p. 31). Indeed, this exact incremental transitioning was observed during the first observation over breakfast, in which a camper wanted to know, in specific detail, what the order of events for the day would be. A counselor, understanding that this camper needed to practice being able to adapt to the unknown, outlined the day's schedule briefly, but did not fully explain the day's events: "I don't know, you're just going to have to find out!" This answer forced the camper to confront and adjust to the unfamiliar without fully leaving him to obsess about the complete unknown.

The combination of new experiences, socialization, and comfort resulted in frequent experiments with autonomy. These results are not inherently noteworthy, as Within Henderson, Powell, and Scanlin's (2005) research already quantitatively demonstrated that campers reported an increased sense of independence. However, the present study extended such prior results by allowing campers with ASD themselves to describe significant independent experiences. Although this is the first qualitative study to describe this, the idea that camps can increase independence is not new; within Henderson, Powell, and Scanlin's (2005) research, one of the skills quantitatively measured that significantly improved for campers with ASD was independence. For William, camp provided an opportunity to practice a necessary adult skill of sleeping alone. 
The researcher's attempt to organize and focus findings within collective identity theory led to mixed results. Unfortunately, many of the themes initially coded for collective identity theory were not represented as much as presumed. As already stated, although Ernest did mention his own identification of traits of autism and how other campers had this in common, none of the other campers remarked as to how they shared a collective identity with their peers with ASD. This may be explained by a couple factors. First, the nature of autism is that individuals experience difficulties in thinking abstractly (Soloman, Buaminger, \& Rogers, 2011). In order to place yourself in a social category, you must be able to look at yourself objectively, an ability that requires abstract thought. This also may be due to the interview questions not relating enough to collective identity. The communicative limitations of ASD may have necessitated more explicit questions in order to foster campers' self-examination. Both of these ideas need to be kept in mind when attempting future research.

Finally, the recurrent theme of improvement of social skills was less explicitly represented within discussions, even if the product of gains in social skills, such as increased socialization, friendship, and positive emotions, was. Nevertheless, some evidence of this theme is supported by the second observation conducted, which occurred during daily social skills instruction. All throughout, campers were observed engaging in the lesson, which was about ways to begin and end a conversation. Having been divided into teams, the counselor leading the lesson asked each group, in turn, to provide a unique way to end a conversation. Responses were varied: "goodbye", "see you later", talk to you soon", and "nice to see you". This was just one moment from thirty minutes of direct social skills instruction that undoubtedly had some effect on campers, as supported by the quantitative gains measured in the SSIS-RS.



Figure 1. Reciprocal relationships of independence, belonging, and self-confidence

\section{Implications}

Overall, findings indicate that the camp was a beneficial, if not transformative experience for its participants. All of the campers related vastly more positive experiences and benefits than negative, and all of the research questions were answered, at least to some degree.

Through examination of interview responses, it is clear that camp provided a meaningful experience to its campers. Data suggests that campers, more than anything, experienced a fun, relaxed, judgment-free, and friendly atmosphere that promoted belonging through interaction with trained counselors and like-minded individuals. Furthermore, they 
appreciated the safety and security the camp staff offered them, which in turn allowed them to partake in new, exploratory experiences. Related to this, the research questions asked whether campers experience belonging, increased self-confidence, and new experiences with independence. Themes that emerged during analysis feed directly into these questions: the importance of having fun, socialization, security, and, to a lesser extent, a collective identity indicate that campers do feel a sense of belonging at camp that they do not experience elsewhere. Furthermore, several experiences regarding independence and concurrent increases in self-confidence were related, such as Jason's story of scaling the rock wall. This, along with other data, indicated that camp resulted in increased self-confidence and autonomy. In fact, the two concepts are so closely related as to be reciprocal: the more independence is exhibited by trying new things, the more self-confidence is bolstered, which in turn encourages independence, and so on. Additionally, neither experimentation with independence or gains in self-confidence would be possible without the sense of comfort and belonging repeatedly expressed by campers. Ultimately, to answer the primary research question, the meaning of camp was derived from the interplay between independence and self-confidence housed within a sense of belonging (see Figure 1). Camp is a welcoming, non-judgmental environment where adolescents with ASD make new friends, practice independence and social skills, experience unique opportunities and settings, and grow personally. These findings were bolstered by being in line with prior data regarding the benefits of social skills camps for children with ASD (Maich, Hall, van Rhijn, \& Quinlan, 2015; Mitchell, Mrug, Patterson, Bailey, \& Hodgens 2015; Rutherford \& Schreiber, 2015; Walker, Barry, \& Bader, 2010).

As for the effectiveness of the photovoice methodology in eliciting responses from participants, it is hard to say. In order to determine the answer to this question, one would need to compare responses from a control group with responses from this group. Anecdotally, photovoice seemed extremely helpful in guiding the interviews and extracting data from a population with inherent communicative difficulties. The researcher believes it shows promise in its efficacy as a qualitative research methodology, especially for individuals with ASD. Further research needs to be conducted comparing its efficacy for interviewing individuals with ASD with other qualitative methodologies.

\section{Limitations}

There were limitations to this study. First, the small sample size limits the ability to generalize findings to the overall population. Also, the limited time-frame by which the study was allowed to acquire data prevented the researcher from conducting repeated, more focused interviews, as well as conduct follow-up interviews after a period of time. Also, it is possible that as the researcher attempted to extract information from the terse participants, statements could have been inadvertently coerced from participants that they would not have made otherwise. Additionally, while the quantitative data does support the idea that some campers experience growth in social skills from their time at camp, it does not support the same idea definitively. Only four camper's experienced overall growth, while two remained the same, and two decreased. As to why William and David indicated a decrease, it is possible that the quantitative measure was too linguistically challenging for either to accurately answer. Ideally, one would have evaluation documentation to reinforce this, but the researcher was unable to acquire such data prior to the study. In lieu of such, it is possible to examine the duration of each participants' individual interviews. By far, David's interview was the shortest, punctuated with one or two word statements that were difficult to derive meaning from. William's interview was similarly short and lacking depth, although he did make a better effort to strive to answer questions effectively. In theory, the researcher posits that if there were evaluation data, such as linguistic IQ scores, you could see that the individuals with the lowest verbal skills correlate with the lack of gains in social skills indicated by the SSIS-RS. Lastly, the researcher's position as both a working counselor for the camp and researcher may have influenced objectivity; future research would be better served with a more objective researcher.

There were lessons learned during the course of this study that might inform similar future research. If possible, a follow-up qualitative inquiry with the same participants during their second year of camp should be conducted. This would have provided an opportunity to further hone questioning to more directly derive answers related to whether the participants related to collective identity theory. The researcher would also like to hear more about specific instances that resulted in transformative experiences, similar to Jason climbing the rock wall or William sleeping in his own bed. Also, the researcher would attempt to obtain more demographic data to more fully represent the campers for readers, as well as evaluation data to potentially reinforce findings. Finally, if possible, it would be a good idea to employ other researchers to expand the sample group further to assist in generalizability of results. 